\title{
Clinical efficacy data on gene tests trails marketing in psychiatry
}

For psychiatric patients today, finding the right drug at the right dose is almost always a matter of trial and error. In recent months, companies have come forward with what they say is a solution to this problem: new commercial genetic tests that purport to predict optimal drug dosing and help avoid adverse events. The arrival of these tests on the market has ignited a debate, however, as many psychiatrists worry that evidence demonstrating their benefit is lacking.

"There's not enough prospective data with most of these genes to as yet guide clinical practice," says Anil Malhotra, director of the Laboratory of Molecular Psychiatry at the Zucker Hillside Hospital, a psychiatric facility in Glen Oaks, New York.

That doesn't mean that researchers and companies aren't trying to fill the data gap. One of the first such prospective, randomized studies was reported in late May in Phoenix at an annual psychopharmacologic conference known as the New Clinical Drug Evaluation Unit meeting. A team led by Kevin Furmaga at the Pine Rest Christian Mental Health Services in Grand Rapids, Michigan, randomly assigned 51 people with depression to receive either a test called GeneSightRx Psychotropic, which tests for a handful of DNA polymorphisms linked to drug metabolism and response, or treatment as usual. All participants swabbed their cheeks for DNA but subsequently didn't know whether their care was guided by pharmacogenomics. Clinicians who scored the patients' outcome measures were also blinded to which study subjects received the pharmacogenomic test.

Although the trial proved too small to yield statistically significant results, the majority of the 26 participating psychiatrists used the test to either choose or confirm their primary treatment. Furthermore, the pharmacogenetically guided therapy yielded a trend toward improved clinical outcomes, with half the subjects receiving the test responding to their therapy compared to only a quarter in the treatment-as-usual arm.

Currently, the US Food and Drug Administration requires drug labels to contain information about pharmacogenetic biomarkers for 26 different psychiatric medications, including many best-selling antidepressants and antipsychotics such as Celexa (citalopram) and Risperdal (risperidone). These label warnings are based on many studies that have demonstrated correlations between certain mutations in certain liver-detoxifying enzymes and drug

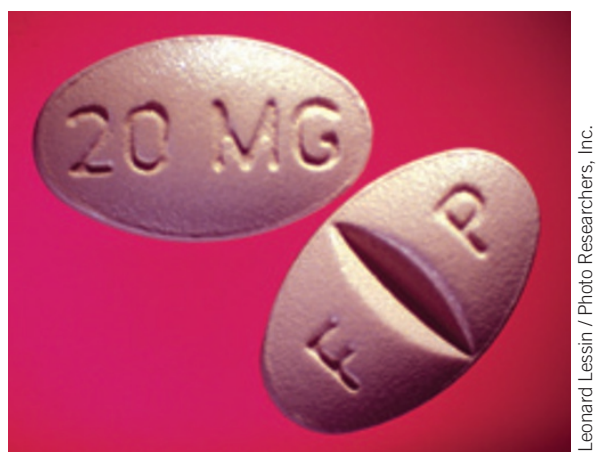

How do you do: Genes up Celexa response.

responses. Yet, few of these labels offer much in the way of clinical recommendations for how to use this information.

Diagnostics companies are forging ahead with a fix. On 28 June, California-based Millennium Laboratories started marketing a test to physicians that analyzes variations in genes encoding enzymes associated with the metabolism of drugs commonly prescribed to people suffering from pain, anxiety, depression or insomnia. The month before, AssureRx Health rolled out GeneSightRx ADHD, which measures variations in three genes linked with response to medications routinely used to treat attention deficit hyperactivity disorder. It is the second product from the Ohio company, which began selling the GeneSightRx Psychotropic test in 2010 .

According to AssureRx's president and chief executive James Burns, both GeneSightRx tests "are easy; they're actionable and they're immediately applicable in a clinical setting."

\section{Predictive guidance}

Many psychiatrists welcome these new testssome to guide drug choice, but the majority for dosing decisions. "I think we know a lot more about trying to prevent side effects than good drug response," says David Mrazek of the Mayo Clinic in Rochester, Minnesota, who wrote the 2010 textbook Psychiatric Pharmacogenomics and sits on AssureRx's scientific advisory board. "Although it would be great to tell patients that this drug will work for them, we're not there yet."

Given the preliminary state of the science, Roy Perlis, director of the Psychiatry Center for Experimental Drugs and Diagnostics at the Massachusetts General Hospital in Boston, thinks the tests should only be rolled out for a subset of mental health patients. "It would absolutely be a mistake at this point to get these tests in everyone," Perlis says. "My suspicion is that these kinds of tests may be more useful for patients who have failed multiple treatments and not gotten better than they are for all comers."

That remains a hypothesis at this point, but it's a testable one-and most companies in the field are now actively engaged in clinical research to assess how best to market their products. Last year, for example, AssureRx, together with scientists at the New Jerseybased Medco Research Institute, launched a 2,000-person study to examine whether drug adherence rates are higher and medical claims less frequent for people who receive the GeneSightRx Psychotropic test, all of whom must have recently switched or added antidepressant and antipsychotic drugs, compared to matched controls from Medco's databases.

Genomind, the Pennsylvania-based startup behind a ten-gene psychiatric pharmacogenetic test called Genecept, which has been commercially available for about a year now, is similarly sponsoring a handful of both open-label and blinded studies to assess the company's assay in people with tough-totreat depression. "We take the science very seriously," says Nancy Grden, general manager of Genomind, which counts both Perlis and Malhotra on its scientific advisory board. "We know [the test] is not the be-all and end-all, but it's certainly better than the trial and error that's going on today, and we think it is important to have as much data as possible to share for the whole discipline."

The issue of cost also remains unresolved at this point. In one of the only published models to date, Perlis and his colleagues estimated the sticker price of using pharmacogenomic testing to decide between two classes of antidepressants relative to the next best strategy of simply prescribing one type of drug first and then switching sequentially if treatments don't work. Assuming a test costs $\$ 500$, which is in the right ballpark for most of today's products, Perlis's team calculated that, for a 40-year-old with major depression, each quality-adjusted life year gained because of pharmacogenomic testing would cost close to $\$ 100,000$, which is on the border of what economists say is a costeffective measure (Neuropsychopharmacology 34, 2227-2236, 2009).

"There are a lot of questions about the use of genetic testing in psychiatry," notes Furmaga. "But this is the direction that the research has to take if [psychiatric pharmacogenetic testing] is going to be a legitimate technology with credibility."

Elie Dolgin 